\title{
Multidisciplinary digital competencies of pre-service vocational teachers
}

\author{
Michael J. J. Roll ${ }^{1 *}$ (D) and Dirk Ifenthaler ${ }^{1,2}$ (1)
}

\section{${ }^{*}$ Correspondence:}

roll@bwl.uni-mannheim.de

${ }^{1}$ University of Mannheim,

L4, 1, 68161 Mannheim,

Germany

Full list of author information

is available at the end of the

article

\begin{abstract}
Developments of Industry 4.0 require a set of multidisciplinary digital competencies for future vocational teachers, consisting of specific knowledge, motivational aspects, cognitive abilities and skills to fulfill the demands of digitally interconnected work situations. The competence model that is adapted from future work scenarios of vocational apprentices in Industry 4.0 includes attitudes towards digitization and handling of digital devices, information literacy, application of digital security standards, virtual collaboration, digital problem solving as well as a demonstration of reflective judgment of one's actions in an interconnected and digital environment. Structural equation modeling was used to assess $N=205$ pre-service vocational teachers between 18 and 35 years of age. The findings indicate the relationship of the proposed dimensions, measured through external- and self-assessments validate the proposed structure of the multidisciplinary digital competencies. However, attitude towards digitization can predict the self-efficacy of the relevant Multidisciplinary Digital Competencies but not the actual achievement in an external assessed scenario. Nevertheless, this study confirms that self-assessed multidisciplinary digital competencies can predict achievement in an external and qualitative-assessed competence test. Fit indices show an acceptable model conception, the reliability and construct validity of the model were confirmed. Findings suggest that the attitude towards digitization and the application of digital security standards are important, whereas the ability to solve digital problems seems to have a weak relation to the general multidisciplinary digital competencies of pre-service vocational teachers.
\end{abstract}

Keywords: Industry 4.0, Multidisciplinary digital competencies, Structural equation modeling, Pre-service vocational teachers

\section{Introduction}

The current digital changes in the industrial world of work are often referred to as the "fourth industrial revolution" or Industry 4.0 (Acatech 2016; Mertens et al. 2017). While originally this was a German particularity, research on the topic is constantly growing in many different fields worldwide and is no longer limited to German industry (Belinski et al. 2020; Liao et al. 2017). In this paper, Industry 4.0 is understood as the horizontally and vertically interconnected digitization of entire industrial value chains. This includes the real-time data exchange between customers, employees, objects and systems via cyber-physical systems (CPS). This turns industrial value chains into value-adding

(c) The Author(s) 2021. This article is licensed under a Creative Commons Attribution 4.0 International License, which permits use, sharing, adaptation, distribution and reproduction in any medium or format, as long as you give appropriate credit to the original author(s) and the source, provide a link to the Creative Commons licence, and indicate if changes were made. The images or other third party material in this article are included in the article's Creative Commons licence, unless indicated otherwise in a credit line to the material. If material is not included in the article's Creative Commons licence and your intended use is not permitted by statutory regulation or exceeds the permitted use, you will need to obtain permission directly from the copyright holder. To view a copy of this licence, visit http://creativeco mmons.org/licenses/by/4.0/. 
networks (Gebhardt et al. 2015; Kagermann et al. 2013). Within these value-adding network, smart products, which carry operational data for their own individual building plans (Weyer et al. 2015), communicate with self-organized and decentralized cyberphysical production systems (CPPS). The resulting smart production lines enable batch size 1 production with maximum cost efficiency (Wilbers 2017). This interconnection facilitates adaptation to spontaneous changes in the environment (Hecklau et al. 2016). A particularity of working in Industry 4.0 is that the contents of work change due to the interconnection, the real-time transmission of data due to CPS and the increasing automation of production.

Even if most studies on Industry 4.0 are still visionary or conceptual in nature (Veile et al. 2019), publications already focus on the resulting and necessary changes of occupational structures and work activities as well as additional requirements for employees, i.e., digital competencies (Gronau et al. 2017; Hecklau et al. 2016; Hummel et al. 2015; Tisch and Metternich 2017), such as procurement of information and holistic thinking ability (Spöttl et al. 2016). There are already numerous studies on digital competencies (Carretero et al. 2017; Ferrari, 2013; Fraillon et al. 2013, 2019; Ilomäki et al. 2016) and twenty-first century skills (Ananiadou and Claro, 2009; Siddiq et al. 2016; van Laar et al. 2017, 2020). However, few studies have been conducted on the digital competencies of technical vocational students (Seufert 2020; Spöttl et al. 2016; Tenberg and Pittich 2017). These often have one thing in common: in the mostly explorative approaches, the pool of experts is very broad and stakeholders who are not directly involved in the training are often interviewed. This somewhat dilutes the statements of the respective studies (Hambach et al. 2017; Spath et al. 2013; Ziegler and Tenberg 2020). Based on two previous exploratory studies which focused on German corporate instructors and (technical) vocational teachers regarding required multidisciplinary digital competencies for future technical vocational students, Roll and Ifenthaler (2020a) suggest that multidisciplinary digital competencies consist of specific knowledge, motivational aspects, cognitive abilities and skills, which technical vocational students in Germany require in order to be prepared for the upcoming changes of Industry 4.0. The multidisciplinarity identified in these two exploratory studies is based on the findings of Tenberg (2020) and Walker et al. (2016) that, due to the interconnectedness of Industry 4.0, it is important in the various training professions to possess multidimensional digital and multidisciplinary skills and abilities that are not purely professional or purely technological to in order to face multidisciplinary problems. Accordingly, multidisciplinary digital competencies should be understood from a dispositional perspective in which they are the sum of various motivational and cognitive competence dimensions (Blömeke et al. 2015).

Teaching all kinds of Industry 4.0-related competencies in the twenty-first century requires correspondingly competent teachers (Instefjord and Munthe 2017; Maderick et al. 2015; Rubach and Lazarides 2019) and therefore a change in the competencies of technical vocational students has implications for all educational stakeholders in the vocational and educational training (VET) system (Sloane 2019). For example, school development will change because teachers must ensure that lessons are developed in such a way that the current state of digitization is discussed and the corresponding digital competencies are developed alongside current subject-related ones (Seufert et al. 2018). 
In addition to the subject-related changes that Industry 4.0 brings to technical and commercial vocational school teachers, new adjustments of multidisciplinary perspectives are also highly relevant for general vocational teaching (Kutscha 2017). Technical vocational students must also be prepared in schools for the multidisciplinary challenges of Industry 4.0 (Wittmann and Weyland 2020). In addition to subject-related competencies, research is increasingly showing that all kinds of digital competencies such as dealing with IT security (Sîmandl et al. 2017) or Information Literacy (Scherer et al. 2017) are becoming important in the vocational classroom (Seufert 2020). However, there is a need to address this issue, because the training of vocational school teachers is not systematically prepared for developing such competencies, and there is no empirical evidence describing the level of multidisciplinary digital competencies of vocational teachers (Gössling et al. 2020; Tenberg 2020).

Self-assessment is a legitimate instrument to obtain information about the multidisciplinary digital competencies of pre-service vocational teachers in a resource-efficient manner (Calvani et al. 2008). But multiple or single choice questions are not fitting for every dimension of a multidisciplinary digital competencies framework (Calvani et al. 2008). Self-assessment in general can only measure competence indirectly (Meritt et al. 2005) and studies show that especially with regard to computer-related competencies, individuals tend to overestimate their skills and abilities (Ihme and Senkbeil 2017). However, self-assessment can determine self-efficacy by asking for the participants' own subjective assessment of whether they are capable of dealing with specific situations (Bandura 1982).

Another measurement technique requires observation of a large group over a longer time (Calvani et al. 2008) or a qualitative approach via semi-structured interviews (Lundkvist and Gustavsson 2018). In contrast to Maderick et al. (2015) and their objective assessment via multiple choice questions, this study provides a qualitative approach to assessing pre-service vocational teachers' multidisciplinary digital competencies. Guzmán-Simón et al. (2017) recommend a qualitative measurement approach to provide further insights into obtained quantitative data. Accordingly, the focus of the study is to investigate the paths of the various competence dimensions of multidisciplinary digital competencies identified in an exploratory study (Roll and Ifenthaler 2020a) among pre-service vocational school teachers through self- and external qualitative assessment. Specifically, this study has three aims: (1) to validate the proposed structure of the multidisciplinary digital competencies; (2) to examine the influence of attitude towards digitization on self- and externally assessed multidisciplinary digital competencies; and (3) to investigate the prediction of the externally and qualitatively assessed multidisciplinary digital competencies through self-assessment of multidisciplinary digital competencies.

\section{Theoretical framework}

Given the numerous concepts of competencies (e.g. Ferrari 2013; Ilomäki et al. 2011), literacies (e.g. Fraillon et al. 2013; Meyers et al. 2013; Pettersson 2017) and 21st century skills (van Laar et al. 2017) in the digital context, the variety of meanings can be irritating (Ilomäki et al. 2016; Pettersson 2017; Weinert 2001). A specific research stream involves the models dealing with the integration of technology in the classroom that examine when, why, how and with what quality teachers integrate digital technologies 
into their lessons - for example, the will, skill, (access to technological) tool model, which the authors expanded by a pedagogical dimension in 2016 (Knezek and Christensen 2016). It shows how teachers' attitudes towards digital technologies, skills and technological equipment determine whether or not they integrate digital technologies into their lessons (Petko 2012). Another model for examining pedagogical, content and technological knowledge is the TPACK model by Mishra and Köhler (Schmid et al. 2020; Tondeur et al. 2020). It can be used as a basis, but taking into consideration that the present model does not explicitly ask for content knowledge, but for multidisciplinary competencies. Furthermore, this study is not intended to ask whether and how pre-service teachers have a pedagogical understanding of how to teach this interdisciplinary and technical content (Mishra and Koehler 2006).

The dispositional sum of multidisciplinary digital competencies, which is presented in the following, can be located in the competence dimension of technological knowledge in the TPACK model (Koehler et al. 2014). In the following, however, the focus is on whether pre-service vocational teachers also have the multidisciplinary digital competencies that are required of technical vocational students in Industry 4.0. Multidisciplinary digital competencies are thought of as competencies that orientate themselves on the changing work environments brought about by the implementation of Industry 4.0 (Gebhardt et al. 2015; Ifenthaler 2018; Sommer 2015; Veile et al. 2019). Multidisciplinary digital competencies specifically address the "necessary and sufficient conditions" of "tasks, goal and success criteria" (Weinert 2001, p. 51) related to Industry 4.0.

Multidisciplinary digital competencies, however, do not stand in contradiction with a domain-specific focus (Weinert 2001). Domain-specific skills, abilities and knowledge are crucial for solving complex problems within a specific domain (Weinert 2001). The focus of multidisciplinary digital competencies lies in the demanding problems of an interconnected Industry 4.0 work environment. Therefore, multidisciplinary digital competencies affect all professions that have to deal with Industry 4.0, regardless of their main discipline. Besides, if domain is described as a "universe of tasks and responses" (Shavelson 2010, p. 46) the universe of Industry 4.0 and its specific digital tasks marks multidisciplinary digital competencies as a domain-specific competence model. Vocational teachers require knowledge, abilities and skills in their specific subject domains (Rausch and Wuttke 2016). Considering the change of work requirements through Industry 4.0 (Ifenthaler 2018) pre-service vocational teachers should have digital competencies that are not only bound to their subject but are multidisciplinary (Roll and Ifenthaler 2020b). Based on the statements of corporate instructors, multidisciplinary digital competencies combine specific dimensions of several digital competencies or digital literacy frameworks to ensure that an individual has the willingness, abilities and skills to behave adequately, individually and socially responsibly in the digital context of professional, social and private situations (Roll and Ifenthaler 2020a, b). Figure 1 shows the seven dimensions of multidisciplinary digital competencies: (1) attitude towards digitization, (2) handling of digital devices, (3) Information Literacy, (4) application of digital security, (5) collaboration due to digital communication, (6) solving of digital problems and (7) reflection on the interconnected and digital environment. 


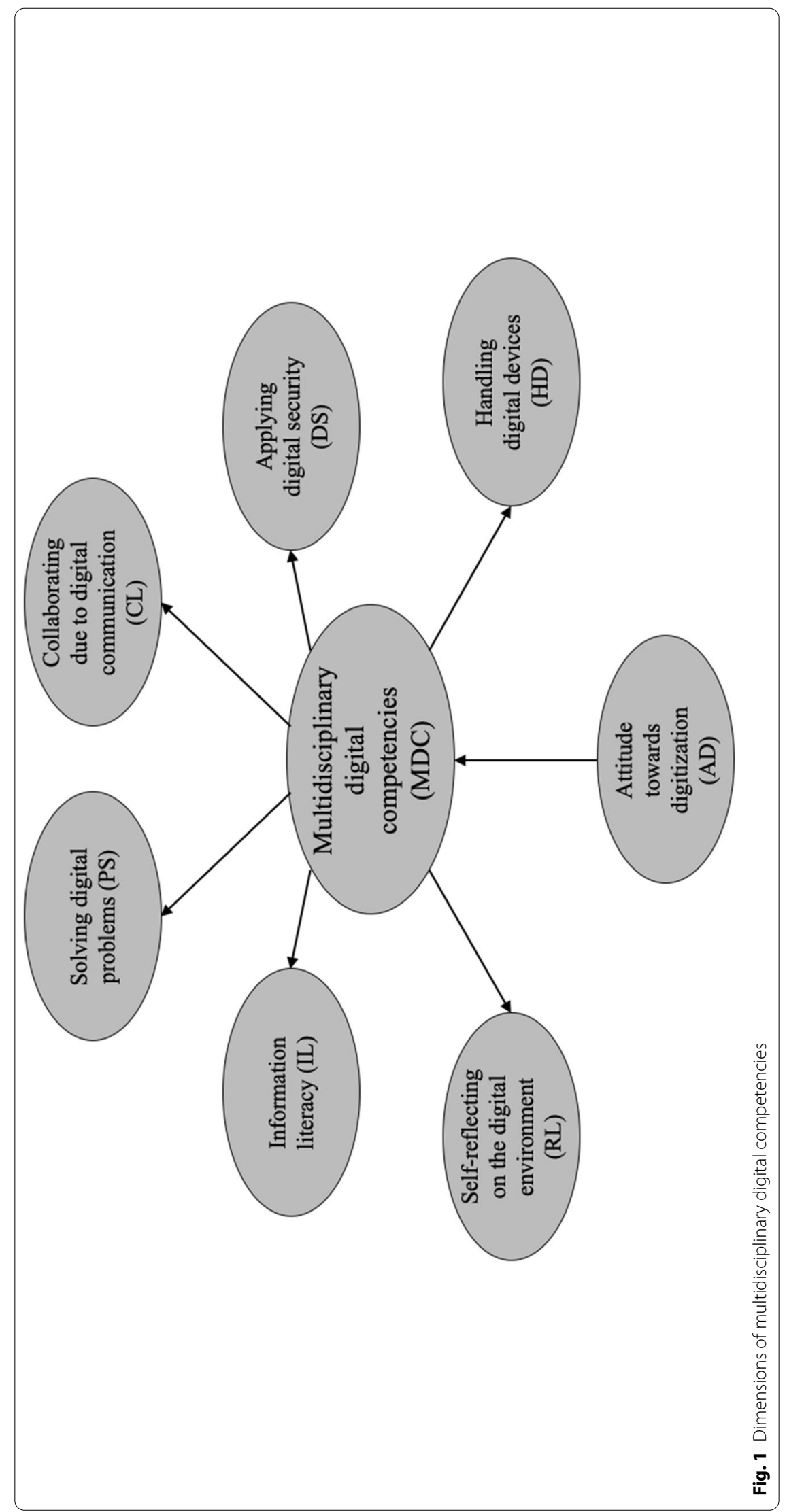




\section{Attitude towards digitization}

The interviewed corporate instructors in Roll and Ifenthaler (2020a) emphasized a positive attitude towards learning and working with digital devices as essential for all kinds of work in Industry 4.0 (Roll and Ifenthaler 2020a). Ferrari (2012) indicates that an integration of attitude is the key difference between a digital literacy framework and digital competencies models. Weinert (2001) describes attitude as the motivational, volitional and social willingness to act. For example, a positive attitude towards digitization can foster the self-efficacy beliefs of pre-service vocational teachers for technology integration in the classroom (Farjon et al. 2019; Lee and Lee 2014; van Braak et al. 2004). Knezek and Christensen (2016) identified willingness as the greatest predictor in their will, skill, tool model. Therefore, attitude towards digitization (AD) is a predictor for this suggested theoretical framework of multidisciplinary digital competencies.

\section{Handling of digital devices}

Pre-service vocational teachers who want to integrate digital devices in the classroom need to know how to deal with the associated daily challenges (Koehler et al. 2014). Ilomäki et al. (2016) state that "technology-oriented terms describing general competences are diminishing in research papers" (Ilomäki et al. 2016, p. 668), but the handling of digital devices (HD) is still fundamental to models of digital competencies (Selwyn and Husen 2010) due to the growing number of portable digital devices (Delcker et al. 2016; Martin and Ertzberger 2013) This competence dimension includes both the handling of physical devices and the efficient use of corresponding software (Johnson et al. 2006; Roll and Ifenthaler 2020a). The term "handling" emphasizes the action-oriented and practical use of digital devices (Calvani et al. 2012). Therefore handling of digital devices includes skills such as "basic computer operations, email, Internet, word processing programmes and presentation programmes" from "technology proficiency" (Mah and Ifenthaler 2018, p. 122). But handling of digital devices does not involve programming skills (Fraillon et al. 2013).

\section{Information literacy}

Based on the concept of the future "knowledge worker" (Tenberg and Pittich 2017), it is important from a company trainer's perspective to have a certain degree of Information Literacy (IL) (Roll and Ifenthaler 2020a). Information Literacy refers to accessing, analysing, evaluating and adequately communicating information (Fraillon et al. 2013, 2014, 2019). In contrast to media literacy, Information Literacy focuses on the procedural knowledge of managing information from static texts rather than understanding accordingly edited information (Fraillon et al. 2013, p. 17). Due to the large amount of information available, and to the fact that it can be incorrect, it is increasingly challenging for an individual to evaluate the authenticity, reliability and validity of information (Bundy 2004). That is why using information responsibly and safely is part of Information Literacy (Fraillon et al. 2019) and part of the multidisciplinary digital competencies framework. 


\section{Application of digital security}

In addition to Information Literacy, the application of digital security (DS) is usually a main dimension of digital competencies frameworks (Carretero et al. 2017; Ferrari 2013; Vuorikari et al. 2016). Sommer (2015) identified the mishandling of data security issues as a major problem in Industry 4.0, especially for small and medium-sized enterprises (SME). Corporate instructors also added that this refers not just to the work, but also to the carefree private presence on the Internet of young people (Roll and Ifenthaler 2020a). It is becoming increasingly important to learn about application of digital security in school to develop adequate skills in this competence dimension (Fraillon et al. 2019; Sîmandl et al. 2017; Šimandl and Vaníček 2017). As a result, employees and teachers should know how to apply digital security measures (Šimandl and Vaníček 2017). Application of digital security deals, for example, with the impact of malware, the simple securing of digital devices and networks, creation of safe passwords, identity theft, risks of digital communication (e.g. phishing emails), and sharing private and work-related information (Sîmandl et al. 2017).

\section{Virtual collaboration due to digital communication}

The more devices are integrated in daily routine, the more popular virtual collaboration (CL) with digital communication devices becomes (Carretero et al. 2017; Ferrari 2013). Adequate digital communication is often directly linked to the manner and rules of virtual collaboration. Therefore collaboration implies skills in communicating via digital devices, exchanging information and negotiating with mutual respect (van Laar et al. 2017). This affects the choice of suitable communication tools for specific situations (private vs. work-related situations) and an appropriate verbal diction towards achieving a common goal. Corporate instructors, interviewed by Roll and Ifenthaler (2020a), claimed that vocational teachers should integrate virtual communication habits in the classroom in order to develop their students' multidisciplinary digital competencies.

\section{Solving of digital problems}

Interconnectivity through Industry 4.0 often helps in decision making processes through "generating, collecting, and processing required information" (Abdel-Basset et al. 2019, p. 2). However, with growing interconnectivity the complexity increases (Arnold et al. 2017). Complex problem solving is described as crucial for the 21th century (Eseryel et al. 2011). The corporate instructors added that it is certainly not a new requirement calling for better problem solving skills, but in an increasingly networked world, such skills are of great importance (Roll and Ifenthaler 2020a). As a result, in order to be digitally competent teachers need skills in digital problem solving (PS) within the digital and interconnected context (Grzybowska and Łupicka 2017; Müller et al. 2018). Therefore, structuring and planning a strategy to solve digital problems is required. In addition, it also requires Information Literacy skills, such as comparing, evaluating and selecting information from the current problem (Grzybowska and Łupicka 2017).

\section{Self-reflecting on the digital environment}

The digital environment is becoming increasingly complex due to Industry 4.0 and the interconnection of CPS in private, work and educational situations (Arnold et al. 2017). 
It is crucial to understand the consequences of ones' own digital actions and to selfreflect about one's actions in the interconnected and digital environment (RF) (Roll and Ifenthaler 2020a). Reflection is systematic and ensures a continuity of learning (Lin et al. 2014). Therefore reflection within the interconnected and digital context of Industry 4.0 affects the individual attitude towards digitization (Ferrari 2012) and the development of multidisciplinary digital competencies in general. Chen, Kinshuk, Wei and Liu (2011) argue that reflection skills are crucial for gathering and evaluating new information. Following Dewey (1910), Rodgers (2002) interprets reflection as a meaning-making process that encourages a deeper understanding of the respective content and its consequences. As a result, RF includes the ability to reflect on one's own actions within an interconnected world. This includes actions in private situations, such as sharing personal photos, but also affects the individual's workplace. However, RF implies an understanding of the consequences of the specific working steps within a supply chain network.

\section{Research questions and hypotheses}

The three aims of this study are (1) to validate the proposed structure of the multidisciplinary digital competencies, (2) to examine the influence of attitude towards digitization on self- and externally assessed multidisciplinary digital competencies, and (3) to validate the prediction of the external and qualitative multidisciplinary digital competencies assessment through the self-assessment of multidisciplinary digital competencies. The first research objective focuses on the proposed structure and related model fit of the multidisciplinary digital competencies model of Roll and Ifenthaler (2020a). To develop students' multidisciplinary digital competencies, vocational teachers must also possess the corresponding multidisciplinary digital competencies (Maderick et al. 2015). Therefore, the first research question aims to validate the influences of variables shown in Fig. 1. Accordingly, it is assumed that the theoretical dimensional structure of multidisciplinary digital competencies can be confirmed in this study (Hypothesis 1).

The second research objective focuses on the effect of attitude towards digitization on multidisciplinary digital competencies for pre-service vocational teachers (Petko 2012). The literature indicated a significant relationship between attitude towards digitization and self-assessed digital competencies (Bunz et al. 2007; Lee and Lee 2014; Pamuk and Peker 2009; Scherer et al. 2017; Wu and Tsai 2006). Yerdelen-Damar et al. (2017) found that pre-service teachers' attitudes towards the use of digital devices had a direct influence $(\beta=0.20)$ on their self-efficacy beliefs in terms of the technological pedagogical content knowledge (TPACK-S). Other studies have confirmed a relationship between attitude towards digitization and self-efficacy (Prior et al. 2016), but focused less on the relationship between attitude towards digitization and actual performance. In a study by Aesaert et al. (2015), the authors neglect the relationship between these two variables. Bunz et al. (2007), meanwhile, found an influence of attitude on self-efficacy, but no relationship between attitude and performance. While Aesaert et al. (2015) clearly had younger participants in their study, the participants examined by Bunz et al. (2007) were first-year university students. In the following, based on the advanced studies and experience of the participants, the authors assume that the attitudes towards digitization also have an influence on multidisciplinary digital competencies. Accordingly, it is expected 
that attitude towards digitization (AD) influences the self-assessed multidisciplinary digital competencies (Hypothesis 2a) because attitude can be a predictor of self-assessed competencies (Yerdelen-Damar et al. 2017). And since attitude toward digitization is a driver for the use of digital media in education (Rubach and Lazarides 2019), it is expected that attitude towards digitization $(A D)$ influences the external and qualitatively assessed multidisciplinary digital competencies (Hypothesis $2 \mathrm{~b}$ ).

The third research objective focuses on how self-assessment may predict the score of the external and qualitative assessment of multidisciplinary digital competencies. This would be indicated by an effect of self-assessed multidisciplinary digital competencies (SAMDC) on the achievement in QAMDC. The meta study by Multon et al. (1991) shows that self-assessed competencies correlate with actual performance. In addition, Hatlevik et al. (2015) found that self-efficacy predicts actual digital competencies. Due to the central assumptions of self-efficacy and performance, the third research question investigates the prediction on the actual performance of multidisciplinary digital competencies, externally and qualitatively assessed, through the self-assessment of multidisciplinary digital competencies (Bandura 1986; Pajares 1996) of pre-service vocational teachers. If pedagogical content knowledge positively influences the quality of teaching (Backfisch et al. 2020), then one can expect that the self-assessed multidisciplinary digital competencies, as specific advanced technological knowledge of the TPACK model, influence the quality of the actually displayed multidisciplinary digital competencies. Hence, following the findings of Hatlevik et al. (2015), it is assumed that self-assessed digital multidisciplinary competencies (SAMDC) can predict achievement in externally and qualitatively assessed multidisciplinary digital competencies (QAMDC) positively (Hypothesis 3).

\section{Method}

\section{Participants}

The participants of this study were $N=222$ students of business and economic education at a European university. Seventeen were deleted from the dataset because they rushed through the online instruments. The critical threshold of minimum time needed to answer all questions truthfully was set at $25 \mathrm{~min}$ before the study $(M=40.48$; $S D=9.02)$. Participants were between 18 and 35 years old $(M=22.78 ; S D=2.89 ; 64.9 \%$ female; $74.1 \%$ undergraduates). At $N=205$, the rule of thumb for critical $C N=200$ is just exceeded. Exceeding $C N$ indicates that its particular structure equation model could adequately reproduce an observed covariance structure (Bagozzi and Yi 2012; Hoelter 1981; Kline 2015). Of these 205 participants, 48 (23.49\%) completed vocational training themselves prior to their studies to become vocational teachers. While business and economics are the major subjects within their study programme, the pre-service vocational

Table 1 Minor subjects of participating pre-service vocational teachers

\begin{tabular}{llllllll}
\hline & Social science & Linguistics & IT & $\begin{array}{l}\text { Natural } \\
\text { sciences }\end{array}$ & $\begin{array}{l}\text { Physical } \\
\text { education }\end{array}$ & Other & $\begin{array}{l}\text { No subject } \\
\text { chosen yet }\end{array}$ \\
\hline Frequency & 35 & 31 & 6 & 6 & 5 & 2 & 120 \\
Percentage & 0.17 & 0.15 & 0.03 & 0.03 & 0.02 & 0.01 & 0.59 \\
\hline
\end{tabular}


teachers also have to choose a second subject to subsequently teach in schools (see Table 1). They usually choose their second subject in the fifth semester of their bachelor course, thus explaining why, at the time of this study, $58.5 \%$ had not yet chosen a subject. Sixty-one students were in the second semester, three in their third, and fifty-six participants stated that they were currently in the fourth semester and therefore had not had the chance to choose a second subject.

\section{Instruments and procedure}

In order to measure the declarative and procedural knowledge of the competence dimensions, measuring instruments were developed to measure the respective constructs through self-assessment as well as through scaling of responses to scenariobased tasks (Blömeke et al. 2015). The participants were invited to a computer room, where they received instructions via a presentation and a link to a website, which led to the two instruments-first a self-assessment questionnaire, and then a survey with open questions. Figure 2 shows the second order measurement model including the two instruments SAMDC and QAMDC and how the dimensions of multidisciplinary digital competencies influence them.

\section{Self-Assessed multidisciplinary digital competencies (SAMDC)}

SAMDC is an instrument for measuring the self-efficacy of the several dimensions of multidisciplinary digital competencies. Therefore, it contains seven latent variables, which are presented in Table 2. Each of these consists of four items, which were measured through self-assessed five-point Likert scales. Within SAMDC the participants had the options "strongly agree", "agree", "neutral", "disagree" or "strongly disagree" with regard to the given statements. The reliability and the descriptive statistics are shown in Table 2. Cronbach's alpha indicates that the internal consistency is acceptable $(\alpha \geq 0.7)$ for all dimensions used within the model except self-reflection (Bagozzi and Yi 2012), Cronbach's alpha of RF was not improved by removing any items. However, because SAMDC measures the individual's own judgement on its multidisciplinary digital competencies, the construction of the latent variable SAMDC made the integration of selfreflection obsolete, because SAMDC already reflects the judgment as a self-efficacy variable (Bandura 1986). This follows Roll and Ifenthaler's (2020b) exploratory study, in which vocational teachers ranked self-reflection as less important than the other multidisciplinary digital competencies. The self-assessed constructs are marked in the following with an "S" in front of the actual construct abbreviation (for example, the self-assessment for the competence dimension handling of digital devices (HD) is called SHD).

\section{Externally and qualitatively assessed multidisciplinary digital competencies (QAMDC)}

The dimensions of multidisciplinary digital competencies were rated through qualified and trained researchers following criteria of qualitative content analyses. Attitude towards digitization and RF were not integrated into external and qualitative assessment of multidisciplinary digital competencies, because self-assessment seemed to be 


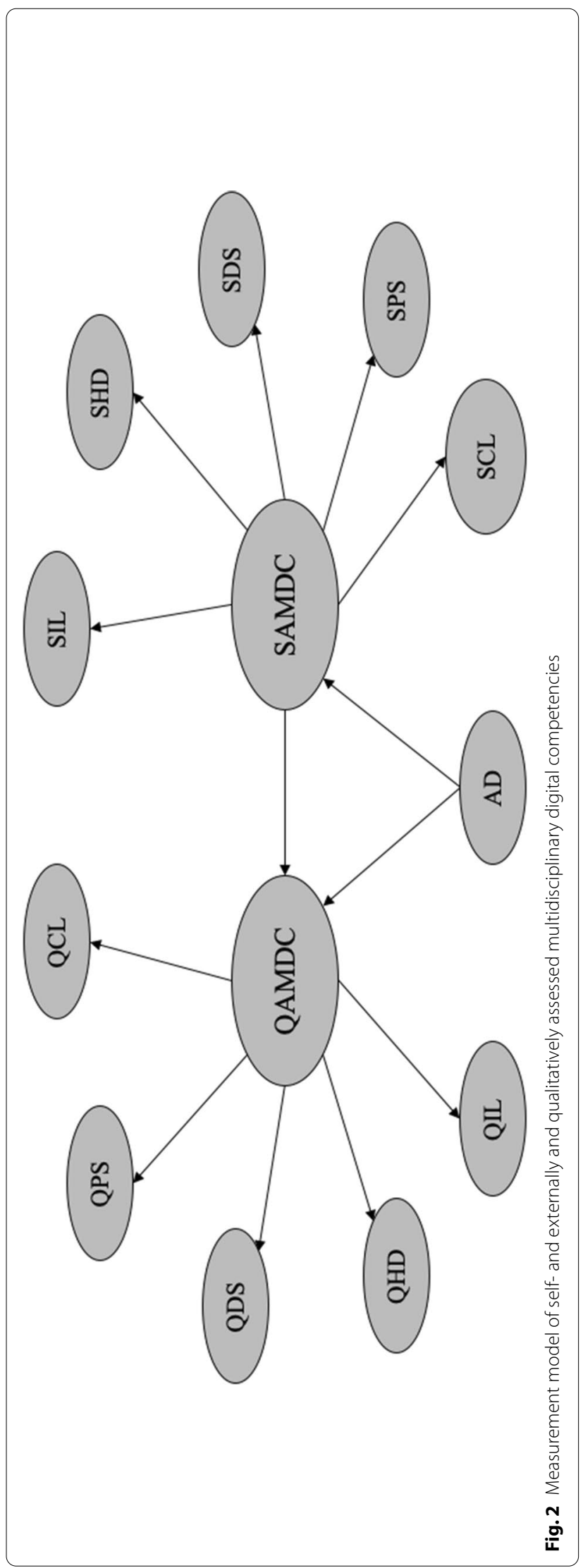


Table 2 Summary of self-assessed scales

\begin{tabular}{llllllllrll}
\hline & Items & Min & Max & $\mathbf{M}$ & SD & $\mathbf{a}$ & Skewness & Kurtosis & SE & N \\
\hline AD & 4 & 2.33 & 5 & 4.00 & 0.71 & 0.79 & -0.58 & -0.21 & 0.05 & 205 \\
SHD & 4 & 1 & 5 & 2.04 & 0.85 & 0.71 & 0.85 & 0.45 & 0.06 & 205 \\
SIL & 4 & 1.75 & 5 & 3.95 & 0.77 & 0.79 & -0.54 & -0.22 & 0.05 & 205 \\
SDS & 4 & 1 & 5 & 2.80 & 0.92 & 0.80 & 0.02 & -0.51 & 0.06 & 205 \\
SCL & 4 & 1.25 & 5 & 3.74 & 0.77 & 0.80 & -0.49 & -0.04 & 0.05 & 205 \\
SPS & 4 & 1.4 & 4.7 & 3.53 & 0.74 & 0.71 & -0.43 & 0.14 & 0.04 & 205 \\
RF & 4 & 2 & 5 & 3.76 & 0.62 & 0.61 & -0.57 & 0.63 & 0.05 & 205 \\
\hline
\end{tabular}

Min minimum, Max maximum, $M$ mean, SD standard deviation, a Cronbach's alpha, SE standard errors, $N$ number of participants; $A D$ attitude towards digitization, $S H D$ self-assessed handling of digital devices, SIL self-assessed information literacy, SDS self-assessed application of digital security, SCL self-assessed collaboration, SPS self-assessed solving of digital problems, $R F$ reflecting on interconnected and digital environment

an adequate method of evaluating these two dimensions (Grant et al. 2002; Richter et al. 2000). QAMDC is designed as a fictive general work scenario. Within this problem setting, participants are asked to imagine that they work in a small to medium sized enterprise in the production sector, which is financially limited but it is under pressure to digitize processes. The participants are employees for the administration and have several tasks to deal with, such as procurement, human resources and marketing. Their supervisor has asked for a presentation about "Industry 4.0 and opportunities" for the firm. This scenario was divided into several questions and tasks, which were adapted from van Deursen and Van Dijk (2010) and created on the base of the particular examples of the DigComp 2.1 framework by Carretero et al. (2017):

- QHD-including what basic and advanced software would be helpful to solve the specific tasks (QBasc and QAdvc),

- QIL-explaining the strategy of searching for, structuring (QIorg) and evaluating information from the internet (QIeva),

- QDS-questioning how to handle upcoming security threats within the scenario (QShnd),

- QCL-questioning how you would collaborate via digital devices with

a) your new supervisor and

b) and old friend of yours, in terms of communication tools and rules (QCL).

- QPS-explaining how to deal with upcoming routine/well-structured problems, such as a sudden dysfunctional Internet connection (QProu), and writing down strategies for solving further complex ill-structured problem settings (QPcrt) (Seel et al. 2009).

QAMDC is based on a qualitative research approach, where participants had to answer open-ended survey questions (Hsieh and Shannon 2005) that were directly related to the given scenario. Responses to these questions were clustered by three qualified raters into a five-point Likert scale. The criteria to assess the responses were pre-tested and defined within a workshop. The constructs evaluated in this way are marked in the following with a "Q" before the actual construct abbreviation (for example, the self-assessment for the competence handling of digital devices (HD) is called QHD). Table 3 shows the interrater reliability and a summary of the assessed tasks. The interrater reliability, calculated via the Intraclass correlation (ICC3,1), demonstrated the two-way mixed consistency 
Table 3 Intraclass correlation (ICC3.1) and summary of externally and qualitatively assessed competence dimensions

\begin{tabular}{llllllllll}
\hline \multicolumn{2}{l}{ Construct } & Raters & ICC & $\mathbf{F}$ & $\mathbf{p}$ & Lower bound & Upper bound & $\mathbf{M}$ & $\mathbf{N}$ \\
\hline QHD & QBasc & 3 & 0.80 & 13 & 0.000 & 0.76 & 0.84 & 3.57 & 205 \\
& QAdvc & 3 & 0.84 & 17 & 0.000 & 0.81 & 0.87 & 3.23 & 205 \\
QIL & Qlorg & 3 & 0.69 & 7.8 & 0.000 & 0.63 & 0.75 & 3.20 & 205 \\
& Qleva & 3 & 0.77 & 11 & 0.000 & 0.72 & 0.81 & 3.58 & 205 \\
QDS & QDS & 3 & 0.84 & 17 & 0.000 & 0.81 & 0.87 & 3.29 & 205 \\
QCL & QCL & 3 & 0.77 & 11 & 0.000 & 0.73 & 0.82 & 3.38 & 205 \\
QPS & QProu & 3 & 0.65 & 6.5 & 0.000 & 0.58 & 0.71 & 3.12 & 205 \\
& QPcrt & 3 & 0.85 & 18 & 0.000 & 0.82 & 0.88 & 3.10 & 205 \\
\hline
\end{tabular}

ICC intraclass correlation coefficient, $F$ F-Test, $p$ probability, $M$ mean, $N$ number of participants, $Q H D$ externally and qualitatively assessed handling of digital device, QBasc externally and qualitatively assessed basic handling of digital devices, QAdvc externally and qualitatively assessed advanced handling of digital devices, QIL externally and qualitatively assessed external and qualitative-assessed Information Literacy, Qlorg externally and qualitatively assessed organization of information, Qleva externally and qualitatively assessed evaluation of information, QDS externally and qualitatively assessed application of digital security, QCL externally and qualitatively assessed collaboration, QPS externally and qualitatively assessed solving of digital problems, QProu externally and qualitatively assessed solving routine problems, QPcrt externally and qualitatively assessed solving of problems creatively

(Shrout and Fleiss 1979) of the three raters. Therefore, the scores in QAMDC can be compared with the self-assessed scores of the latent variables in SAMDC.

\section{Analytic strategy}

To validate hypothesis 1 , structural equation modelling (SEM) was used to evaluate the relations of the dimensions in SAMDC and QAMDC. SEM can test direct effects between constructs. This was used to validate Hypothesis $2 \mathrm{a}$ and Hypothesis $2 \mathrm{~b}$, because the applied SEM also contains the regression analysis for the influence of attitude towards digitization on SAMDC and QAMDC. The measurement model integrates the internal consistency within the dimensions of SAMDC and the assessments of the three qualified raters of QAMDC. By integrating all covariations and influences of the relevant dimensions, the SEM used shows the direct effect of SAMDC on QAMDC (Hypothesis 3). Due to the lack of normal distribution (Table 2), for the final SEM (with SAMDC and QAMDC) the robust maximum likelihood estimator (MLR) was used and adjusted through the Yuan-Bentler correction. Due to the settings of the applied selfprogrammed online survey tools, participants could not finish SAMDC and QAMDC if boxes had been left blank. Therefore, there was no missing data to deal with. To analyse the model of Fig. 2, the statistics software R (version 3.6.1), R-Studio (version 1.1.463) and the R-package lavaan (version 0.6-7) were used (Rosseel 2019; Steinmetz 2015).

\section{Results}

\section{Confirmation of the dimensional structure (Hypothesis 1)}

An adequate model fit is essential to confirm that the model properly represents the data (Hooper et al. 2008). The SEM of Fig. 2 shows a fit of $\chi^{2}(846, N=205)=1105.378$, $p=0.000$, Comparative Fit Index $(\mathrm{CFI})=0.938$, Tucker Lewis Index $(\mathrm{TLI})=0.934$, Root Mean Square Error of Approximation (RMSEA) $=0.039$ and Standardized Root Mean Square Residual $(\mathrm{SRMR})=0.071$. According to Bagozzi and Yi (2012), one can reduce 


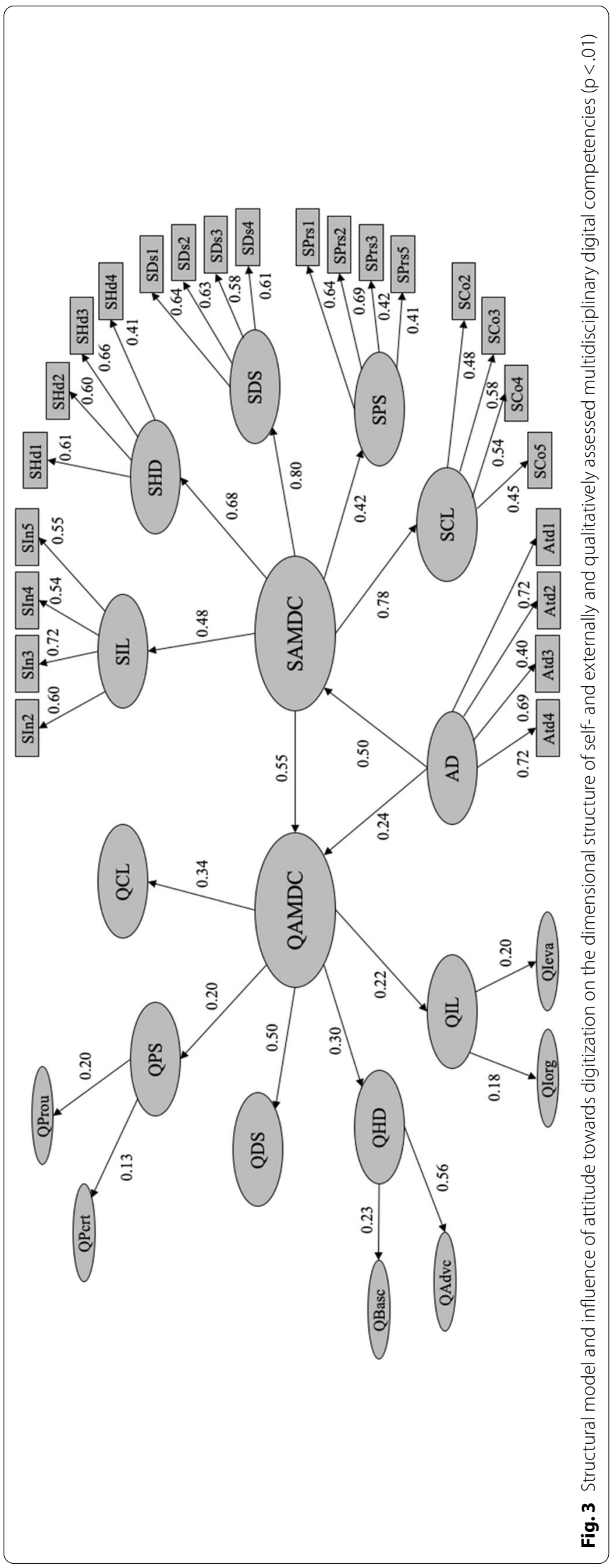


Table 4 Path estimates of the structural model

\begin{tabular}{lllll}
\hline & Estimates & SE & z-value & $\boldsymbol{p}$ \\
\hline AD_SAMDC & 0.501 & 0.134 & 3.738 & 0.000 \\
SHD_SAMDC & 0.682 & 0.161 & 4.235 & 0.000 \\
SDS-SAMDC & 0.797 & 0.226 & 3.529 & 0.000 \\
SCL_SAMDC & 0.783 & 0.185 & 4.228 & 0.000 \\
SPS-SAMDC & 0.418 & 0.117 & 3.578 & 0.000 \\
AD_QAMDC & 0.241 & 0.177 & 1.361 & 0.174 \\
QHD_QAMDC & 0.299 & 0.115 & 1.758 & 0.079 \\
QIL_QAMDC & 0.220 & 0.125 & 2.595 & 0.009 \\
QDS-QAMDC & 0.499 & 0.143 & 3.487 & 0.000 \\
QCL-QAMDC & 0.345 & 0.131 & 2.641 & 0.008 \\
QPS-QAMDC & 0.196 & 0.105 & 1.860 & 0.063 \\
SAMDC-QAMDC & 0.553 & 0.226 & 2.442 & 0.015 \\
\hline
\end{tabular}

$A D$ attitude towards digitization, SHD self-assessed handling of digital devices, SIL self-assessed Information Literacy, SDS self-assessed application of digital security, SCL self-assessed collaboration, SPS self-assessed solving of digital problems, QHD externally and qualitatively assessed handling of digital devices, QIL externally and qualitatively assessed Information Literacy, $Q D S$ externally and qualitatively assessed application of digital security, $Q C L$ externally and qualitatively assessed collaboration, QPS externally and qualitatively assessed solving of digital problems, SAMDC self-assessed multidisciplinary digital competencies, $Q A M D C$ externally and qualitatively assessed multidisciplinary digital competencies

the stringent cut off rules that CFI and TLI are $\geq 0.95$ to CFI $\geq 0.93$ and TLI $\geq 0.92$ if SRMR $\leq 0.07$. Considering the unsatisfactory internal consistency of RF (see Table 2) and the fact that SAMDC measures the individual's judgment of their multidisciplinary digital competencies (Bandura 1986), it was decided to modify the model and not integrate RF (Grant et al. 2002) any further. Overall, the structural equation model now shows a good fit of $X^{2}(689, N=205)=863.001, p<0.001, \mathrm{CFI}=0.956, \mathrm{TLI}=0.952$, RMSEA $=0.035$, SRMR $=0.068$. To examine the relations within the model in Fig. 3, Table 4 shows the path estimates of the structural model. Hypothesis 1 is accepted because the significant path estimates and the fit indices confirm the theoretical dimensional structure of multidisciplinary digital competencies.

\section{Effects of attitude towards digitization on self- and externally and qualitatively assessed multidisciplinary digital competencies}

Hypothesis 2a explores the relationship between pre-service vocational teachers' attitudes towards digitization and their self-assessed of multidisciplinary digital competencies, which was analysed through structural equation modelling. Figure 3 shows a medium standard regression weight of attitude towards digitization to SAMDC and Table 4 confirms its significance at a more conservative level $(\beta=0.5, p<0.000)$. Therefore, hypothesis $2 \mathrm{a}$ is accepted.

Hypothesis $2 \mathrm{~b}$ investigates the effects of pre-service vocational teachers' attitudes towards digitization and their achievement in QAMDC, which was also analysed using structural equation modelling. Figure 3 and Table 4 present a small but not significant standardized regression weight of attitude towards digitization towards QAMDC $(\beta=0.24, p=0.174)$. Hypothesis $2 \mathrm{~b}$ is rejected because of its level of significance of $p>0.05$. 
Prediction of external and qualitative assessment of multidisciplinary digital competencies through self-assessment

Hypothesis 3 examines whether the self-assessed digital multidisciplinary competencies (SAMDC) can positively predict achievement in externally and qualitatively assessed multidisciplinary digital competencies (QAMDC). As can be seen in Fig. 3 and Table 4, SAMDC significantly predicts the achievement in QAMDC $(\beta=0.55, p=0.015)$. Therefore, Hypothesis 3 is accepted because $p<0.05$.

When exploring dependencies in a structural equation model one has to be aware of the adverse effects of multicollinearity (Mansfield and Helms 1982). To test the model on multicollinearity the variance inflation factors (VIF) of each predicting variable were calculated (Mansfield and Helms 1982). A maximum of 1.53 of the VIFs meet the-surely debatable (O'Brien 2007; Thompson et al. 2017)—rule of thumb that they must be less than 4 (O'Brien 2007).

\section{Discussion}

Based on the fact that no significant differences regarding SAMDC and QAMDC were found between pre-service vocational teachers with and without vocational training, it can be assumed that the following results might also be interesting for the implementation of multidisciplinary digital competencies in the dual vocational education and training system.

To explore the misfit of SEM, fit indices are essential, and the results show that all fit indices support the primary hypothesis, whether the model can be validated or not (Cheung and Rensvold 2002; Marsh et al. 2005). The decision about whether the SEM fits is based on four widely known fit indices, which provide an insight in the model's ability to reproduce an input covariance matrix (Bagozzi and Yi 2012; Hooper et al. 2008; Taasoobshirazi and Wang 2016). This study is based on the usual "goodness of fit" indices (GFIs), namely the Confirmatory Fit Index (CFI) and the Tucker-Lewis Index (TLI) (Hooper et al. 2008; Hoyle and Panter 1995; Taasoobshirazi and Wang 2016). Applying clear cut-off criteria, CFI and TLI should be $\geq 0.95$ (Hu and Bentler 1998; Rigdon 1996). These severe values (Bagozzi and Yi 2012) were achieved after excluding RF from the SEM. Absolute fit indices gauge a "badness of fit" (BFI), which means that a value of zero would indicate an optimal fit (Hoyle and Panter 1995). An absolute fit index is the Root Mean Square Error of Approximation (RMSEA), which depends on $N$. Considering $N=205$ in this study, the RMSEA should be less than 0.06 (Hu and Bentler 1998, 1999). Another absolute fit index is the Standardized Root Mean Square Residual (SRMR) (Taasoobshirazi and Wang 2016), which should not be higher than 0.08 (Hooper et al. 2008; Hu and Bentler 1998, 1999). By excluding RF, the absolute fit indices met these cut off criteria and the model fit became acceptable. Due to the good fit of the model there was no need to apply modification indices and change the model any further (MacCallum et al. 1992).

The estimates in Table 4 that relate to QAMDC are less strong than those that are associated with SAMDC, but the relative path estimates are similar. The estimates of the used latent variables to QAMDC are small to medium and not as highly significant as the self-assessed latent variables. The standardized path coefficients between SAMDC to SDS and SCL are quite high in Fig. 3. The dimension application of digital security 
with SDS and QDS has the greatest impact on SAMDC or QAMDC. SCL and QCL have the second largest estimates. The constructs for handling of digital devices are in third position and Information Literacy in fourth. The externally and qualitatively measured variable of Information Literacy (QIL) has a weak estimate on QAMDC, while SIL has a medium path estimate on SAMDC. Solving of digital problems seems to have the weakest bound to multidisciplinary digital competencies. In conclusion, the model shows an acceptable fit and Table 4 provides mostly significant path coefficients.

The second hypothesis examined the influence of the attitude towards digitization on the participants' multidisciplinary digital competencies. The results show that the attitude towards digitization influences the self-assessed multidisciplinary digital competencies of pre-service vocational teachers. This significance confirms the finding of Yerdelen-Damar et al. (2017) that pre-service teachers' attitudes towards technology use had an effect on their technological competence. The hypothesized assumption (Hypothesis $2 \mathrm{~b}$ ) that the attitude towards digitization would also directly influence the external and qualitative assessment of pre-service vocational teachers' multidisciplinary digital competencies was not verified by this study. However, this supports the findings of Aesaert et al. (2015), who found no relationship "between pupils' ICT attitudes and their actual ICT competence" (Aesaert et al. 2015, p. 67). Whether ICT is implemented in teaching seems to depend on the general mindset of teachers (Hermans et al. 2008; Tearle 2003). The findings confirm the conclusion of Bunz et al. (2007) that there is a direct relationship not between computer anxiety and actual computer-email-web-fluency, but between attitudes and self-perception of the participants. As the data shows, SAMDC could be a good and significant predictor for actual QAMDC. In other words, this study confirms that ICT self-efficacy correlates positively with the achievement in ICT competence tests (Fraillon et al. 2014; Hatlevik et al. 2015). Table 5 shows the latent correlation between the constructs of Fig. 2 . The instruments significantly correlate at an almost medium level and positively with each other $(r=0.48, p<0.0001)$, which is a significant and higher correlation than Ihme and Senkbeil found in $2017(r=0.22, p<0.01)$. This is not surprising because, according to Hargittai and Hinnant (2008), digital competencies usually increase with the level of education, and while Ihme and Senkbeil (2017) focused on adolescents, the present study focuses exclusively on pre-service teachers in their bachelor's or master's programme. Table 5 shows the latent correlations of the corresponding (self-assessed and externally assessed) competence dimensions of the multidisciplinary digital competencies. While the dimensions handling of digital devices, Information Literacy, and application of digital security show weak but significant correlations, no significant correlation between QCL and SCL was found for collaboration. A minimal correlation was found within the dimension problem solving. This is not surprising, because even though the latent constructs aimed at the same content, they measure different realities, since the open questions in QAMDC were designed specifically for a fictive scenario.

\section{Limitations}

Studies which aim to measure digital skills are often limited in their definitions, small sample sizes or methods of data collection (van Deursen and van Dijk 2009). Firstly, the sample was limited to pre-service vocational teachers, who studied business and 


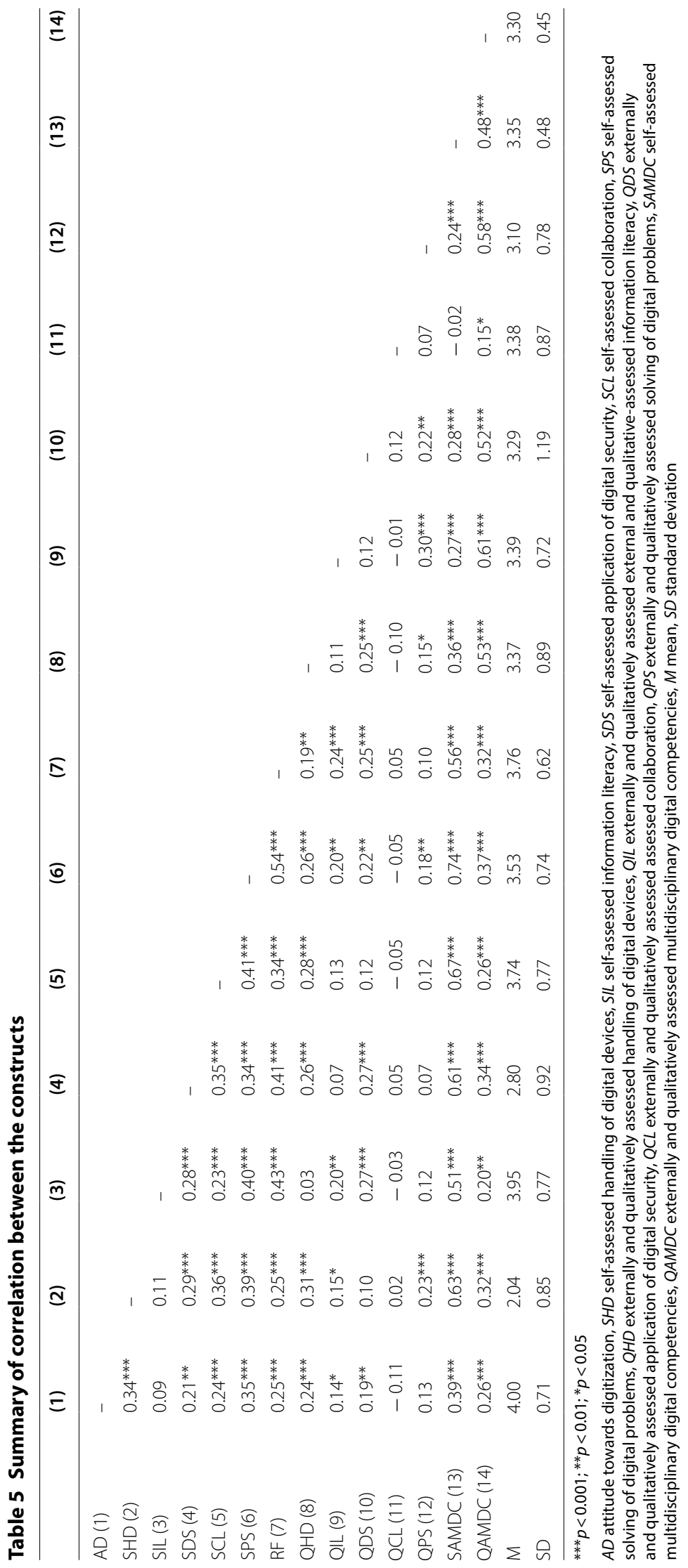


economic education. Consequently, the findings should not be generalized, although the sample size was adequate for applying SEM. Secondly, the self-assessments of preservice vocational teachers should be treated with caution (Aesaert et al. 2017; Ihme and Senkbeil 2017). For this reason, the externally and qualitatively evaluated statements were added as QAMDC. An explanation for the weak to medium path coefficients could be the invalid evaluation of the three raters. However, Table 3 shows an acceptable interrater reliability. Therefore, the low performance of the QAMDC model does not result in multicollinearity or falsifying the items through different ratings of the open-ended questions.

\section{Conclusions}

Based on the explorative studies of Roll and Ifenthaler (2020a, b) on multidisciplinary digital competencies, this study can be seen as a specific conceptual addition to the TK dimension of the TPACK model (Koehler et al. 2014) in the multidisciplinary context of the dual vocational education and training system, because the origin of the multidisciplinary digital competencies dimensions focused on technical vocational students as a target group. As mentioned at the beginning of this paper, teachers should also have these digital competencies in order to be prepared for teaching in Industry 4.0. The results validate the conception of the named dimensions in multidisciplinary digital competencies, with the exception of the construct of reflecting on interconnected and digital environments. The path estimates of SAMDC and QAMDC are slightly different, but this can give pedagogically worthwhile insights into the dimensions that most influence the multidisciplinary digital competencies of pre-service vocational teachers. This could help to foster specific competence development of pre-service vocational teachers within their curricula (Ertmer 2005; Mishra and Koehler 2006). In addition to the education of vocational teachers, the curricula of further education of in-service vocational teachers could also benefit from such studies by specifically focusing on the development of such multidisciplinary digital competencies in training units (Seufert et al. 2018).

Furthermore, the findings indicate that attitude towards digitization has a large effect on the multidisciplinary digital competencies of pre-service vocational teachers (Ifenthaler and Schweinbenz 2013). To integrate digital devices in the classroom, vocational teachers' self-efficacy in this context should be improved during their pre-service training. Looking at the low self-assessment in SHD and comparing it with the higher values in QHD or QAMDC, one notices that most students underestimate their handling of digital devices (Aesaert et al. 2017; Bunz et al. 2007; Dunning et al. 2003). Therefore, digital devices should be increasingly integrated into the training of pre-service vocational teachers to avoid an underestimation and boost their self-efficacy in handling digital devices (Brevik et al. 2019). In particular, a systematic integration of multidisciplinary and digital competencies into the curriculum of vocational teacher education would be of great benefit (Tenberg, 2016, 2020).

In the following studies, a critical reflection on the fictitious scenario and the wording of the tasks is required. Even if measuring digital skills via self-assessment is a resource-saving method, it does not provide accurate evidence of digital competence (van Deursen and Van Dijk 2010). The aim of this study was to test if the approach of 
a formative external and qualitative assessment of open-ended questions could be a resource-saving alternative to modelling complex scenarios via programming specific dashboards (Rausch 2017). Certainly, this is not valid if you want to use it as high-stakes testing. Self-assessment is not really suitable here. The partial convergence of the results with the existing research literature at least indicates that the applied approach is suitable, even if the instrument still needs to be optimized and tested on a larger sample size. This study provides an overview of the general structure of multidisciplinary digital competencies; however, a further investigation of each dimension would be desirable. Furthermore, it would be of interest to apply QAMDC to validate the multidisciplinary digital competencies of technical vocational students, exploring their readiness for Industry 4.0 .

\section{Supplementary Information}

The online version contains supplementary material available at https://doi.org/10.1186/s40461-021-00112-4.

Additional file 1. Appendices.

\section{Abbreviations}

AD: Attitude towards digitization; BFI: Badness of fit; CFI: Confirmatory Fit-Index; CL: Collaboration due to digital communication; CPS: Cyber-physical-systems; CPPS: Cyber-physical-producation systems; DS: Digital security; GFI: Goodness of fit; HD: Handling of digital devices; ICC: Intraclass correlation coefficient; ICT: Information and communication technologies; IL: Information literacy; MDC: Multidisciplinary digital competencies; MLR: Maximum likelihood estimator; QAdvc: External and qualitative-assessed advanced handling of digital devices; QAMDC: External and qualitative-assessed Multidisciplinary Digital Competencies; QBasc: External and qualitative-assessed basic handling of digital devices; QCL: External and qualitative-assessed virtual collaboration due to digital communication; QDS: External and qualitativeassessed application of digital security; QHD: External and qualitative assessed handling of digital devices; Qleva: External and qualitative-assessed evaluation of information; QIL: External and qualitative-assessed information literacy; Qlorg: External and qualitative-assessed organization of information; QPcrt: External and qualitative-assessed solving problems creatively; QProu: External and qualitative-assessed solving routine problems; QPS: External and qualitative-assessed solving of digital problem; RF: Reflecting of interconnected and digital environment; RMSEA: Root Mean Square Error of Approximation; SAMDC: Self-assessed Multidisciplinary Digital Competencies; SCL: Self-assessed virtual collaboration due to digital communication; SDS: Self-assessed application of digital security; SEM: Structural Equation Modeling; SHD: Selfassessed handling of digital devices; SIL: Self-assessed information literacy; SPS: Self-assessed solving of digital problems; SRMR: Standardized Root Mean Square Residual; TLI: Tucker-Lewis-Index; TPACK: Technological pedagogical content knowledge; VET: Vocational and educational training; VIF: Variance inflation factors.

\section{Acknowledgements}

Not applicable.

\section{Authors' contributions}

MR analysed and interpreted the data, he was a major contributor in writing the manuscript. DI was a major contributor in editing and reviewing the manuscript, he wrote several chapters. All authors read and approved the final manuscript.

\section{Funding}

Not applicable.

Availability of data and materials

The datasets generated and/or analysed during the current study are not publicly available due to current analysis within another research project but are available from the corresponding author on reasonable request.

\section{Competing interests}

The authors declare that they have no competing interests.

\section{Author details}

${ }^{1}$ University of Mannheim, L4, 1, 68161 Mannheim, Germany. ${ }^{2}$ Curtin University, Perth, Australia.

Received: 18 June 2020 Accepted: 1 February 2021

Published online: 22 February 2021 


\section{References}

Abdel-Basset M, Manogaran G, Mohamed M, Rushdy E (2019) Internet of things in smart education environment: supportive framework in the decision-making process. Concurr Comput 31(10):1-12. https://doi.org/10.1002/ cpe.4515

Acatech (2016) Kompetenzen für Industrie 4.0: Qualifizierungsbedarfe und Lösungsansätze (acatech Position). Herbert Utz Verlag, Munich, p 1-52

Aesaert K, Van Nijlen D, Vanderlinde R, Tondeur J, Devlieger I, Van Braak J (2015) The contribution of pupil, classroom and school level characteristics to primary school pupils'ICT competences: a performance-based approach. Comput Educ 87:55-69. https://doi.org/10.1016/j.compedu.2015.03.014

Aesaert K, Voogt J, Kuiper E, van Braak J (2017) Accuracy and bias of ICT self-efficacy: An empirical study into students' over- and underestimation of their ICT competences. Comput Hum Behav 75:92-102. https://doi.org/10.1016/j. chb.2017.05.010

Ananiadou K, Claro M (2009) 21st century skills and competences for new millennium learners in OECD countries. OECD Education Working Papers, 41, 33. https://doi.org/https://doi.org/10.1787/218525261154

Arnold C, Kiel D, Voigt K-I (2017) The driving role of the industrial internet of things for strategic change: the case of electronic engineering business models. Proceedings of the 24th Innovation and Product Development Management Conference (IPDMC), Reykjavik, Iceland, 11-13.

Backfisch I, Lachner A, Hische C, Loose F, Scheiter K (2020) Professional knowledge or motivation? Investigating the role of teachers' expertise on the quality of technology-enhanced lesson plans. Learn Instruct 66:1-13. https://doi. org/10.1016/j.learninstruc.2019.101300

Bagozzi RP, Yi Y (2012) Specification, evaluation, and interpretation of structural equation models. J Acad Mark Sci 40(1):8-34. https://doi.org/10.1007/s11747-011-0278-x

Bandura A (1982) Self-percepts of efficacy. J Behav Theo Exp Psychiatry 13(3):195-199

Bandura A (1986) Social foundations of thought and action: a social cognitive theory. Prentice Hall, Upper Saddle River

Belinski R, Peixe AMM, Frederico GF, Garza-Reyes JA (2020) Organizational learning and industry 4.0: findings from a systematic literature review and research agenda. Benchmarking 27(8):2435-2457. https://doi.org/10.1108/ BIJ-04-2020-0158

Blömeke S, Gustafsson JE, Shavelson RJ (2015) Beyond dichotomies: competence viewed as a continuum. Zeitschrift Für Psychologie 223:3-13

Brevik LM, Gudmundsdottir GB, Lund A, Strømme TA (2019) Transformative agency in teacher education: fostering professional digital competence. Teach Teacher Edu 86:1-15. https://doi.org/10.1016/j.tate.2019.07.005

Bundy A (2004) Australian and New Zealand information literacy framework: Principles, standards and practice. https:// adbu.fr/wp-content/uploads/2013/02/Infolit-2nd-edition.pdf

Bunz U, Curry C, Voon W (2007) Perceived versus actual computer-email-web fluency. Comput Hum Behav 23(5):23212344. https://doi.org/10.1016/j.chb.2006.03.008

Calvani A, Cartelli A, Fini A, Ranieri M (2008) Models and instruments for assessing digital competence at school. J E-Learn Knowled Soc 4(3):183-193

Calvani A, Fini A, Ranieri M, Picci P (2012) Are young generations in secondary school digitally competent? A study on Italian teenagers. Comput Educ 58(2):797-807. https://doi.org/10.1016/j.compedu.2011.10.004

Carretero S, Vuorikari R, Punie Y (2017) DigComp 2.1: the digital competence framework for citizens - with eight proficiency levels and examples of use. https://doi.org/https://doi.org/10.2760/38842

Chen NS, Kinshuk, Wei CW, Liu CC (2011) Effects of matching teaching strategy to thinking style on learner's quality of reflection in an online learning environment. Comput Educ 56(1):53-64. https://doi.org/10.1016/j.compe du.2010.08.021

Cheung GW, Rensvold RB (2002) Evaluating goodness-of-fit indeces for testing measurement invariance. Struct Equ Model 9(2):233-255. https://doi.org/10.1207/S15328007SEM0902

Delcker J, Honal A, Ifenthaler D (2016) Mobile device usage in higher education. 13th International Conference on Cognition and Exploratory Learning in Digital Age (CELDA 2016), 27-34. https://doi.org/https://doi.org/10.1109/ ISSA.2016.7802925

Dewey J (1910) How we think. Courier Corporation

Dunning D, Johnson K, Ehrlinger J, Kruger J (2003) Why people fail to recognize their own incompetence. Curr Direct Psychol Sci 12(3):83-87. https://doi.org/10.1111/1467-8721.01235

Ertmer PA (2005) Teacher pedagogical beliefs: the final frontier in our quest for technology integration? Educ Tech Research Dev 53(4):25-39. https://doi.org/10.1007/BF02504683

Eseryel D, Ge X, Ifenthaler D, Law V (2011) Dynamic modeling as a cognitive regulation scaffold for developing complex problem-solving skills in an educational massively multiplayer online game environment. J Educ Comput Res 45(3):265-286. https://doi.org/10.2190/EC.45.3.a

Farjon D, Smits A, Voogt J (2019) Technology integration of pre-service teachers explained by attitudes and beliefs, competency, access, and experience. Comput Educ 130:81-93. https://doi.org/10.1016/j.compedu.2018.11.010

Ferrari A (2012) Digital competence in practice: An analysis of frameworks. doi:https://doi.org/10.2791/82116

Ferrari A (2013) DIGCOMP: A framework for developing and understanding digital competence in europe. In: Punie $Y_{\text {, }}$ Brečko BN (eds.). European Union. https://doi.org/https://doi.org/10.2788/52966

Fraillon J, Ainley J, Schulz W, Duckworth D, Friedman T (2019) IEA International computer and information literacy study 2018 assessment framework. In Fraillon J, Ainley J, Schulz W, Duckworth D, Friedman T (eds.), IEA International Computer and Information Literacy Study 2018 Assessment Framework. Springer Nature Switzerland AG. https:// doi.org/https://doi.org/10.1007/978-3-030-19389-8

Fraillon J, Ainley J, Schulz W, Friedman T, Gebhardt E (2014) Preparing for life in a digital age. Springer, Berlin. https://doi. org/https://doi.org/10.1007/978-3-319-14222-7

Fraillon J, Schulz W, Ainley J (2013) International computer and information literacy study: assessment framework. (IEA), International Association for the Evaluation of Educational Achievement. https://doi.org/https://doi.org/10.15478/ uuid:b9cdd888-6665-4e9f-a21e-61569845ed5b 
Gebhardt J, Grimm A, Neugebauer LM (2015) Developments 4.0_prospects on future requirements and impacts on work and vocational education. J Tech Educ 3(2):117-133

Gössling B, Hagemeier D, Sloane PFE (2020) VET 4.0 as a didactical challenge: How vocational teachers cope with digitalized worlds of work. Zeitschrift Für Berufs- Und Wirtschaftspädagogik 115(4):546-566. https://doi.org/10.25162/ zbw-2019-0022

Grant AM, Franklin J, Langford P (2002) The self-reflection and insight scale: a new measure of private self-consciousness. Soc Behav Personal 30(8):821-836. https://doi.org/10.2224/sbp.2002.30.8.821

Gronau N, Ullrich A, Teichmann M (2017) Development of the industrial loT competences in the areas of organization, process, and interaction based on the learning factory concept. Procedia Manufacturing 9:254-261. https://doi. org/10.1016/j.promfg.2017.04.029

Grzybowska K, Łupicka A (2017) Key competencies for industry. Econ Manag Innovat 1:250-253. https://doi.org/10.26480 /icemi.01.2017.250.253

Guzmán-Simón F, García-Jiménez E, López-Cobo I (2017) Undergraduate students' perspectives on digital competence and academic literacy in a Spanish university. Comput Hum Behav 74:196-204. https://doi. org/10.1016/j.chb.2017.04.040

Hambach J, Tenberg R, Reiß J, Tisch M, Metternich J (2017) Lernkonzepte für eine wandlungsfähige Produktion. J Tech Educ (JOTED) 5(1):100-132

Hargittai E, Hinnant A (2008) Digital inequality: differences in young adults' use of the internet. Commun Res 35(5):602-621. https://doi.org/10.1177/0093650208321782

Hatlevik OE, Ottestad G, Throndsen I (2015) Predictors of digital competence in 7th grade: a multilevel analysis. J Comput Assist Learn 31(3):220-231. https://doi.org/10.1111/jcal.12065

Hecklau F, Galeitzke M, Flachs S, Kohl H (2016) Holistic approach for human resource management in industry 4.0. Procedia CIRP 54:1-6. https://doi.org/10.1016/j.procir.2016.05.102

Hermans R, Tondeur J, van Braak J, Valcke M (2008) The impact of primary school teachers' educational beliefs on the classroom use of computers. Comput Educ 51(4):1499-1509. https://doi.org/10.1016/j.compedu.2008.02.001

Hoelter JW (1981) The analysis of covariance structures - Goodness-of-fit indices. Sociol Methods Res 11(3):325-344

Hooper D, Coughlan J, Mullen MR (2008) Structural equation modelling: guidelines for determining model fit. Electron J Business Res Methods 6(1):53-60. https://doi.org/10.21427/D79B73

Hoyle RH, Panter AT (1995) Writing about structural equation models. In: Hoyle RH (ed) Structural equation modeling - concepts, issues and applications. Sage Publications, Thousand Oaks, pp 1-289

Hsieh H-F, Shannon SE (2005) Three approaches to qualitative content analysis. Qual Health Res 15(9):1277-1288. https://doi.org/10.1177/1049732305276687

Hu L, Bentler PM (1998) Fit indices in covariance structure modeling: sensititvity to underparameterized model misspecification. Psychol Methods 3(4):424-453. https://doi.org/10.1037/1082-989X.3.4.424

Hu L, Bentler PM (1999) Cutoff criteria for fit indexes in covariance structure analysis: conventional criteria versus new alternatives. Struct Equ Model 6(1):1-55. https://doi.org/10.1080/10705519909540118

Hummel V, Hyra K, Ranz F, Schuhmacher J (2015) Competence development for the holistic design of collaborative work systems in the logistics learning factory. Procedia CIRP 32:76-81. https://doi.org/10.1016/j.proci r.2015.02.111

Ifenthaler D (2018) How we learn at the digital workplace. In: Ifenthaler D (ed) Digital workplace learning - bridging formal and informal learning with digital technologies. Springer, Berlin, Heidelberg, pp 3-8

Ifenthaler D, Schweinbenz V (2013) The acceptance of Tablet-PCs in classroom instruction: the teacher's perspectives. Comput Human Behav 29(3):523-534. https://doi.org/10.1016/j.chb.2012.11.004

Ihme JM, Senkbeil M (2017) Why adolescents cannot realistically assess their own computer-related skills. Zeitschrift Für Entwicklungspsychologie Und Pädagogische Psychologie 49(1):24-37. https://doi.org/10.1026/0049-8637/ a000164

Ilomäki L, Kantosalo A, Lakkala M (2011) What is digital competence? Linked Portal 1-12

Ilomäki L, Paavola S, Lakkala M, Kantosalo A (2016) Digital competence-an emergent boundary concept for policy and educational research. Educ Inform Technol 21(3):655-679. https://doi.org/10.1007/s10639-014-9346-4

Instefiord EJ, Munthe E (2017) Educating digitally competent teachers: a study of integration of professional digital competence in teacher education. Teach Teacher Educ 67:37-45. https://doi.org/10.1016/j.tate.2017.05.016

Johnson DW, Bartholomew KW, Miller D (2006) Improving computer literacy of business management majors: a case study. J Inform Technol Educ 5:77-94

Kagermann H, Wahlster W, Helbig J (2013) Recommendations for implementing the strategic initiative INDUSTRIE 4.0. In Final report of the Industrie 4.0 Working Group.

Kline RB (2015) Principles and practice of structural equation modeling. Guilford publications, New York

Knezek G, Christensen R (2016) Extending the will, skill, tool model of technology integration: adding pedagogy as a new model construct. J Comput Higher Educ 28(3):307-325. https://doi.org/10.1007/s12528-016-9120-2

Koehler MJ, Mishra P, Kereluik K, Shin TS, Graham CR (2014) The technological pedagogical content knowledge framework. In: Spector JM, Merill MD, Elen J, Bishop MJ (eds) Handbook of research on educational communications and technology, 4th edn. Springer, Berlin, pp 101-111

Kutscha G (2017) Berufsbildungstheorie auf dem Weg von der Hochindustrialisierung zum Zeitalter der Digitalisierung. In: Bonz B, Schanz H, Seifried J (eds) Berufsbildung vor neuen herausforderungen. Wandel von Arbeit und Wirtschaft. Schneider Verlag Hohengehren GmbH, Baltmannsweiler, pp 17-47

Lee Y, Lee J (2014) Enhancing pre-service teachers' self-efficacy beliefs for technology integration through lesson planning practice. Comput Educ 73:121-128. https://doi.org/10.1016/j.compedu.2014.01.001

Liao Y, Deschamps F, de Freitas Rocha Loures E, Ramos LFP (2017) Past, present and future of industry 4.0: a systematic literature review and research agenda proposal. Int J Prod Res 55(12):3609-3629. https://doi. org/10.1080/00207543.2017.1308576

Lin YT, Wen ML, Jou M, Wu DW (2014) A cloud-based learning environment for developing student reflection abilities. Comput Hum Behav 32:244-252. https://doi.org/10.1016/j.chb.2013.12.014 
Lundkvist AH, Gustavsson M (2018) Conditions for employee learning and innovation: interweaving competence development activities provided by a workplace development programme with everyday work activities in SMEs. Vocations Learning 11(1):45-63. https://doi.org/10.1007/s12186-017-9179-6

MacCallum RC, Roznowski M, Necowitz LB (1992) Model modifications in covariance structure analysis: the problem of capitalization on chance. Psychol Bull 111(3):490-504. https://doi.org/10.1037//0033-2909.111.3.490

Maderick JA, Zhang S, Hartley K, Marchand G (2015) Preservice teachers and self-assessing digital competence. J Educ Comput Res 54(3):326-351. https://doi.org/10.1177/0735633115620432

Mah DK, Ifenthaler D (2018) Students' perceptions toward academic competencies: the case of German first-year students. Issues Educ Res 28(1): 120-137. http://www.iier.org.au/iier28/mah.pdf

Mansfield ER, Helms BP (1982) Detecting multicollinearity. Am Stat 36(1):158-160

Marsh HW, Hau K-T, Grayson D (2005) Goodness of fit in structural equation models. In: Maydeu-Olivares A, McArdle JJ (eds) Multivariate applications book series. Contempory psychometrics: a festschrift for Roderick McDonald. Lawrence Erlbaum Associates Publishers, Mahwah, pp 275-340

Martin F, Ertzberger J (2013) Here and now mobile learning: an experimental study on the use of mobile technology. Comput Educ 68:76-85. https://doi.org/10.1016/j.compedu.2013.04.021

Meritt K, Smith D, Di Renzo JC (2005) An investigation of self-reported computer literacy: is it reliable? Issues Inform Syst 6(1):289-295. https://doi.org/10.1107/S0108270195007803

Mertens P, Barbian D, Baier S (2017) Digitalisierung und Industrie 4.0: Eine Relativierung. Springer, Berlin

Meyers EM, Erickson I, Small RV (2013) Digital literacy and informal learning environments: An introduction. Learn Media Technol 38(4):355-367. https://doi.org/10.1080/17439884.2013.783597

Mishra P, Koehler MJ (2006) Technological pedgogical content knowledge: a framework for teacher knowledge. Teachers College Record 108(6):1017-1054. https://doi.org/10.1002/bjs.7342

Müller JM, Kiel D, Voigt KI (2018) What drives the implementation of industry 4.0? The role of opportunities and challenges in the context of sustainability. Sustainability (Switzerland) 10(1):1-24. https://doi.org/10.3390/su10010247

Multon KD, Brown SD, Lent RW (1991) Relation of self-efficacy beliefs to academic outcomes: a meta-analytic investigation. J Couns Psychol 38(1):3-38. https://doi.org/10.1037/0022-0167.38.1.30

O'Brien RM (2007) A caution regarding rules of thumb for variance inflation factors. Qual Quant 41(5):673-690. https:// doi.org/10.1007/s11135-006-9018-6

Pajares F (1996) Self-efficacy beliefs in academic settings. Rev Educ Res 66(4):543-578. https://doi.org/10.3102/00346 543066004543

Pamuk S, Peker D (2009) Turkish pre-service science and mathematics teachers' computer related self-efficacies, attitudes, and the relationship between these variables. Comput Educ 53(2):454-461. https://doi.org/10.1016/j.compe du.2009.03.004

Petko D (2012) Teachers' pedagogical beliefs and their use of digital media in classrooms: Sharpening the focus of the "will, skill, tool" model and integrating teachers' constructivist orientations. Comput Educ 58(4):1351-1359. https:// doi.org/10.1016/j.compedu.2011.12.013

Pettersson F (2017) On the issues of digital competence in educational contexts: a review of literature. Edu Inf Technol 23:1005-1021. https://doi.org/10.1007/s10639-017-9649-3

Prior DD, Mazanov J, Meacheam D, Heaslip G, Hanson J (2016) Attitude, digital literacy and self efficacy: flow-on effects for online learning behavior. Internet Higher Educ 29:91-97. https://doi.org/10.1016/j.iheduc.2016.01.001

Rausch A (2017) Dispositional predictors of problem solving in the field of office work. Vocat Learn 10(2):177-199. https ://doi.org/10.1007/s12186-016-9165-4

Rausch A, Wuttke E (2016) Development of a multi-faceted model of competence and its acceptance by different stakeholders in the business domain. Unterrichtswissenschaft 44(2):169-184

Richter T, Naumann J, Groeben N (2000) Attitudes toward the computer: construct validation of an instrument with scales differentiated by content. Comput Hum Behav 16(5):473-491. https://doi.org/10.1016/50747 $-5632(00) 00025-X$

Rigdon EE (1996) CFI versus RMSEA: a comparison of two fit indexes for structural equation modeling. Struct Equ Model 3(4):369-379. https://doi.org/10.1080/10705519609540052

Rodgers C (2002) Defining reflection: another look at john dewey and reflective thinking. Teachers College Record 104(4):842-866

Roll M, Ifenthaler D (2020a) Competence development across different learning contexts in industry 4.0. In: Aprea C, Sappa V, Tenberg R (eds) Connectivity and integrative competence development in vocational and professional education and training. Franz Steiner Verlag, Stuttgart, pp 185-209

Roll M, Ifenthaler D (2020b) The impact of learning factories on multidisciplinary digital competencies. In Wuttke $\mathrm{E}$, Seifried J, Niegemann H (eds.), VET and professional development in the age of digitalization (pp. 23-38).

Rosseel Y (2019) The lavaan tutorial. https://lavaan.ugent.be/tutorial/tutorial.pdf

Rubach C, Lazarides R (2019) Eine Skala zur Selbsteinschätzung digitaler Kompetenzen bei LehramtsstudierendenA measure for teacher students'self-evaluated digital competencies scale. Zeitschrift Für Bildungsforschung 9(3):345-374. https://doi.org/10.1007/s35834-019-00248-0

Scherer R, Rohatgi A, Hatlevik OE (2017) Students' profiles of ICT use: identification, determinants, and relations to achievement in a computer and information literacy test. Comput Hum Behav 70:486-499. https://doi. org/10.1016/j.chb.2017.01.034

Schmid M, Brianza E, Petko D (2020) Developing a short assessment instrument for technological pedagogical content knowledge (TPACK.xs) and comparing the factor structure of an integrative and a transformative model. Comput Edu 157:1-12. https://doi.org/10.1016/j.compedu.2020.103967

Seel N, Ifenthaler D, Pirnay-Dummer P (2009) Mental models and problem solving: technological solutions for measurement and assessment of the development of expertise. In Blumschein P, Hung W, Jonassen D, Strobel J (eds.), Model-based approaches to learning. SensePublishers, Rotterdam. https://www.sensepublishers.com/media 1659-model-based-approaches-to-learning.pdf\#page $=46$ 
Selwyn N, Husen O (2010) The educational benefits of technological competence: an investigation of students' perceptions. Eval Res Educ 23(2):137-141. https://doi.org/10.1080/09500790.2010.483515

Seufert S (2020) Digitale Kompetenzen in der kaufmännischen Domäne im Kontext der Berufsausbildung in der Schweiz. In Ziegler B, Tenberg R (eds.), Berufsbildung 4.0 - Steht die berufliche Bildung vor einem Umbruch? (pp. 56-73). Barbara Budrich Verlag.

Seufert S, Guggemos J, Tarantini E (2018) Digitale Transformation in Schulen-Kompetenzanforderungen an Lehrpersonen. Beiträge Zur Lehrerinnen- Und Lehrerbildung: Zeitschrift Zu Theorie Und Praxis Der Aus- Und Weiterbildung von Lehrerinnen Und Lehrern 36(2): 175-193. http://nbn-resolving.org/urn:nbn:de:0111-pedocs-170969

Shavelson RJ (2010) On the measurement of results. Empirical Res Vocat Edu Training 2(1):41-63. https://doi.org/10.1016/ S0140-6736(01)34328-3

Shrout PE, Fleiss JL (1979) Intraclass correlations: uses in assessing rater reliability. Psychol Bull 86(2):420-428. https://doi. org/10.1037/0033-2909.86.2.420

Siddiq F, Scherer R, Tondeur J (2016) Teachers' emphasis on developing students' digital information and communication skills (TEDDICS): a new construct in 21st century education. Comput Educ 92-93:1-14. https://doi.org/10.1016/j. compedu.2015.10.006

Sîmandl V, Dobias V, Sery M (2017) The influence of teaching methods on learners' perception of e-Safety. J Inform Technol Educ Innov Pract 16:253-275. https://doi.org/10.1519/R-21636.1

ŠimandI V, Vaníček J (2017) Influences on ICT teachers knowledge and routines in a technical e-safety context. Telematics Inform 34:1488-1502. https://doi.org/10.1016/j.tele.2017.06.012

Sloane PFE (2019) Das Alltägliche der Digitalisierung: Über Scheinriesen, stillschweigende Veränderungen und alte Antworten. Zeitschrift Für Berufs- Und Wirtschaftspädagogik 115(2):175-183. https://doi.org/10.25162/ zbw-2019-0008

Sommer L (2015) Industrial revolution—industry 4.0: are German manufacturing SMEs the first victims of this revolution? J Ind Eng Manag 8(5):1512-1532. https://doi.org/10.3926/jiem.1470

Spath D, Gerlach S, Hämmerle M, Krause T, Schlund S (2013) Produktionsarbeit der Zukunft - Industrie 4.0. Werkstattstechnik 103:130-134. https://doi.org/10.1007/978-3-658-04682-8

Spöttl G, Gorldt C, Windelband L, Grantz T, Richter T (2016) Industrie 4.0: Auswirkungen auf Aus- und Weiterbildung in der $\mathrm{M}+\mathrm{E}$ Industrie. In bayme vbm Studie.

Steinmetz H (2015) Lineare Strukturgleichungsmodelle. Eine Einführung mit R. In Matiaske W, Spieß M (eds.), Sozialwissenschaftliche Forschungsmethoden (9th ed.). Rainer Hampp Verlag.

Taasoobshirazi G, Wang S (2016) The performance of the SRMR, RMSEA, CFI, AND TLI. J Appl Quant Methods 11(3):31-41

Tearle P (2003) ICT implementation — what makes the difference? Br J Edu Technol 34(5):567-583

Tenberg R (2016) How can we get technology taught in schools? J Tech Educ 4(1):1-10

Tenberg R (2020) Editorial: Grundständige digitale Lehrpersonenbildung - nicht in Sicht. J Tech Educ (JOTED) 8(1):16-32

Tenberg R, Pittich D (2017) Apprenticeship 4.0 or just 1.2? Analysis of a technical and operational change and its implications for vocational education in technical domains. J Tech Educ (JOTED) 5(1):26-46

Thompson CG, Kim RS, Aloe AM, Becker BJ (2017) Extracting the variance inflation factor and other multicollinearity diagnostics from typical regression results. Basic Appl Soc Psychol 39(2):81-90. https://doi.org/10.1080/01973 533.2016 .1277529

Tisch M, Metternich J (2017) Potentials and limits of learning factories in research, innovation transfer, education, and training. Procedia Manufacturing 9:89-96. https://doi.org/10.1016/j.promfg.2017.04.027

Tondeur J, Scherer R, Siddiq F, Baran E (2020) Enhancing pre-service teachers'technological pedagogical content knowledge (TPACK): a mixed-method study. Edu Technol Res Dev 68(1):319-343. https://doi.org/10.1007/s1142 3-019-09692-1

van Braak J, Tondeur J, Valcke M (2004) Explaining different types of computer use among primary school teachers. Eur J Psychol Educ 19(4):407-422

van Deursen A, van Dijk J (2009) Using the internet: skill related problems in users' online behavior. Interact Comput 21(5-6):393-402. https://doi.org/10.1016/j.intcom.2009.06.005

van Deursen A, van Dijk J (2010) Measuring internet skills. Int J Human Comput Interact 26(10):891-916. https://doi. org/10.1080/10447318.2010.496338

van Laar E, van Deursen AJAM, van Dijk JAGM, de Haan J (2020) Determinants of 21st-century skills and 21st-century digital skills for workers: a systematic literature review. SAGE Open 10(1):1-14. https://doi.org/10.1177/2158244019 900176

van Laar E, van Deursen A, van Dijk J, de Haan J (2017) The relation between 21st-century skills and digital skills: a systematic literature review. Comput Hum Behav 72:577-588. https://doi.org/10.1016/j.chb.2017.03.010

Veile JW, Kiel D, Müller JM, Voigt KI (2019) Lessons learned from industry 4.0 implementation in the German manufacturing industry. J Manuf Technol Manag 31(5):977-997. https://doi.org/10.1108/JMTM-08-2018-0270

Vuorikari R, Punie Y, Carretero S, Van Den Brande L (2016) DigComp 2.0: the digital competence framework for citizens. In JRC Science for Policy Report. Doi:https://doi.org/10.2791/11517

Walker F, Link N, Nickolaus R (2016) A multidimensional structure of domain-specific problem-solving competencies of electronics technicians for automation technology. J Sci Educ Tech 8(7):1-16. https://doi.org/10.1186/S4046 $1-016-0034-Z$

Weinert FE (2001) Concept of competence: A conceptual clarification. In Rychen DS, Salganik LH (eds.), Defining and selecting key competencies (pp. 45-65). Hogrefe \& Huber Publishers

Weyer S, Schmitt M, Ohmer M, Gorecky D (2015) Towards industry 4.0: standardization as the crucial challenge for highly modular, multi-vendor production systems. IFAC-PapersOnLine 28(3):579-584. https://doi.org/10.1016/j.ifaco I.2015.06.143

Wilbers K (2017) Industrie 4.0 und Wirtschaft 4.0: Eine Chance für die kaufmännische Berufsbildung. In Wilbers K (ed.) Industrie 4.0: Herausforderungen für die kaufmännische Bildung (pp. 9-52). GmbH

Wittmann E, Weyland U (2020) Berufliche Bildung im Kontext der digitalen Transformation. Zeitschrift Für Berufs — Und Wirtschaftspädagogik 116(2):269-291. https://doi.org/10.25162/zbw-2020-0012 
Wu YT, Tsai CC (2006) University students' internet attitudes and internet self-efficacy: A study at three universities in Taiwan. Cyber Behav 9(4):441-450. https://doi.org/10.1089/cpb.2006.9.441

Yerdelen-Damar S, Boz Y, Aydın-Günbatar S (2017) Mediated effects of technology competencies and experiences on relations among attitudes towards technology use, technology ownership, and self-efficacy about rechnological pedagogical content knowledge. J Sci Educ Technol 26(4):394-405. https://doi.org/10.1007/s10956-017-9687-z

Ziegler B, Tenberg R (2020) Berufsbildung 4.0-Stand und Perspektiven: Zur Einführung in den Band. In Bundesinstitut für Berufsbildung (ed), Berufsbildung 4.0: steht die berufliche Bildung vor einem Umbruch? Barbara Budrich Verlag, $\mathrm{P}$ $5-12$

\section{Publisher's Note}

Springer Nature remains neutral with regard to jurisdictional claims in published maps and institutional affiliations.

Submit your manuscript to a SpringerOpen ${ }^{\circ}$ journal and benefit from:

Convenient online submission

Rigorous peer review

- Open access: articles freely available online

- High visibility within the field

- Retaining the copyright to your article

Submit your next manuscript at $\gg$ springeropen.com 